\title{
Development and Validation of HPTLC Method for Simultaneous Estimation of Emtricitabine, Rilpivirine and Tenofovir Disoproxil Fumarate in Combined Dosage form
}

\author{
J. Saminathan and T. Vetrichelvan \\ Department of Pharmaceutical Analysis, Adhiparasakthi College of Pharmacy, Melmaruvathur-603 319 \\ Kanchipuram Dist, Tamil Nadu, India
}

Received: June 20, 2015; Accepted: December 05, 2015; Published (Web): February 17, 2016

\begin{abstract}
This study describes the development and validation of high performance thin layer chromatographic (HPTLC) method for the simultaneous estimation of Emtricitabine (EMT), Rilpivirine (RPV) and Tenofovir disoproxil fumarate (TFV) in combined dosage form. Chromatographic separation of these drugs was performed on aluminum plates precoated with silica gel $60 \mathrm{~F}_{254}$ as the stationary phase using solvent system consisted of chloroform: ethyl acetate: methanol: glacial acetic acid (5:2:1:0.1 v/v/v/v). The densitometric analysis was carried out in absorbance mode at $272 \mathrm{~nm}$. The drugs were satisfactorily resolved with $\mathrm{R}_{f}$ values of $0.28 \pm 0.02,0.70 \pm 0.02$ and $0.52 \pm 0.04$, respectively. The method was validated according to the International Conference of Harmonization (ICH) guidelines. The calibration curves were linear over the $\left(\mathrm{r}^{2}\right.$ $>0.999$ ) concentrations range from 600-2400 ng band ${ }^{-1}$ for Emtricitabine, 50-300 ng bands ${ }^{-1}$ for Rilpivirine and 600-3600 ng band ${ }^{-1}$ for Tenofovir disoproxil fumarate. The method showed accuracy of $100.01 \%$, $100.32 \%$ and $100.14 \%$ and percentage assay of $99.91 \%, 98.72 \%$ and $99.34 \%$ for Emtricitabine, Rilpivirine and Tenofovir disoproxil fumarate, respectively. Percentage relative standard deviation $(<2 \%)$ was found for both precision and robustness study showing that the proposed method was precise, specificity, robust and stable in accordance with ICH guidelines.
\end{abstract}

Key words: Emtricitabine, rilpivirine, tenofovir disoproxil fumarate, HPTLC, validation

\section{Introduction}

Complera, a combination drug of EMT, RPV and $\mathrm{TFV}$, is used as a complete single-tablet regimen to treat HIV-1 infection in adults. United States Food and Drug Administration (FDA) approved for use in people with HIV who have not previously been treated with antiretrovirals. The newest combination tablet offers complete HIV drug coverage in a single daily dose. EMT, chemically 5-fluoro-1-(2R, 5S)-[2 (hydroxymethyl)-1,3-oxathiolan-5-yl] cytosine (Figure 1a) is nucleoside reverse transcriptase inhibitor (NRTI) with activity against Human Immunodeficiency Virus Type 1 (HIV-1). RPV is chemically known as 4-[[4[[4-[(E)-2-cyanoethenyl]-2, 6 dimethyl phenyl] amino] 2 pyrimidinyl] amino] benzonitrile monohydrochloride (Figure 1b). It is a diarylpyrimidine derivative, a potent non nucleoside reverse transcriptase inhibitor (NNRTI) of the human immunodeficiency virus type 1 (HIV-1). TFV is $9[(R)$ 2[[bis [[(isopropoxycarbonyl) oxy] methoxy] phosphinyl] methoxy] propyl] adenine fumarate (Figure 1c). Both EMT and TFV are included in the official books of United States Pharmacopoeia 2005 and Indian Pharmacopoeia 2014 except Rilpivirine is not official in any of the pharmacopoeias like IP, BP and US Pharmacopoeia. Literature survey reveals that there is no reported HPTLC method for simultaneous determination of EMT, RPV and TFV (Ahindita et al., 2011; Anandakumar et al., 2011; Choudhari et al., 2013; Choudhari et al., 2010; Ghorpade et al., 2010; Ilango et al., 2012; Jayakar et al., 2010; Patel et al., 2009; Sudha et al., 2010) HPLC (Murali et al., 2011; Pranitha et al., 2012; Rao et al., 2011; Rezk et al., 2005) HPTLC (Joshi et al., 2009). The present study was to develop accurate, precise and

Correspondence to: J. Saminathan; E-mail: swamilingam@gmail.com 
sensitive HPTLC method and to validate as per International Conference on Harmonization of Technical Requirements for registration of Pharmaceuticals for human use guidelines (ICH 2005).

\section{Materials and Methods}

Materials and reagents: Pharmaceutical grade EMT, RPV and TFV working standard were obtained as a gift samples from Strides Arcolabs Ltd., Bengaluru, India. The commercially available tablet Complera ${ }^{\circledR}$ containing a combination of EMT- $200 \mathrm{mg}$, RIL-25 mg and TFV-300 mg were procured from Gilead sciences. Analytical grade methanol (Qualigens, India Ltd.), chloroform (Qualigens, India Ltd.) and ethyl acetate (Merck Specialities Private Ltd., Mumbai) were used in the present study.

Equipments and chromatographic conditions: The method development was performed by using Camag HPTLC containing Camag Linomat 5 S/NO.180750 applicator, Hamilton 100 microlitre sample syringe, E. MERCK KGaA silica gel (Art. No.1.05554.0007) precoated plate $60 \mathrm{~F} 254,[(20 \times 10 \mathrm{~cm})$ with $250 \mu \mathrm{m}$ thickness; supplied by Anchrom Techno, Mumbai]. The plates were prewashed with methanol and activated at $120{ }^{\circ} \mathrm{C}$ for 20 min prior to chromatography. A constant application rate of $0.1 \mu 1 \mathrm{~S}^{-1}$ was used and the space between two bands was $6 \mathrm{~mm}$. The slit dimension was kept at $4 \mathrm{~mm} \times 0.30 \mathrm{~mm}$ and the scanning speed was 20 $\mathrm{mmS}^{-1}$. Linear ascending development was carried out in $20 \mathrm{~cm} \times 10 \mathrm{~cm}$ twin trough glass chamber (Camag, Muttenz, Switzerland) saturated with the mobile phase. The optimized chamber saturation time for mobile phase was $30 \mathrm{~min}$ at room temperature $\left(25^{\circ} \mathrm{C} \pm 2\right)$. Densitometric scanning was performed using a Camag TLC scanner III (Camag, Muttenz, Switzerland) in the reflectance-absorbance mode and operated by winCATS software (V1.4.6). The source of radiation used was a deuterium lamp emitting a continuous UV spectrum between 200 and $800 \mathrm{~nm}$. Dissolution of the compounds was enhanced by sonication on a Shimadzu sonicator and REMI centrifuge. The mobile phase was consisted of chloroform: ethylacetate: methanol: glacial acetic acid (5:2:1:0.1, v/v/v/v) and $10 \mathrm{ml}$ of the mobile phase was used for chromatography. All the drugs showed considerable absorbance at $272 \mathrm{~nm}$. So, $272 \mathrm{~nm}$ was selected as the wavelength for detection overlain spectra shown in figure 2 .

Preparation of standard stock solution and calibration curve: Standard stock solutions to get a concentration of $2 \mathrm{mg} / \mathrm{ml}, 0.25 \mathrm{mg} / \mathrm{ml}$ and $3 \mathrm{mg} / \mathrm{ml}$ solution were prepared by using methanol as a diluent. The mixed standard solutions were prepared by dilution of the stock solution with mobile phase to give concentrations ranging from 400-2400 ng/band of EMT, 50-250 ng/band of RPV and 600-3600 ng/band of TFV.

Preparation of sample preparation: Twenty Complera ${ }^{\circledR}$ tablets (each tablet contained $200 \mathrm{mg}$ of EMT, $25 \mathrm{mg}$ equivalent of RPV and $300 \mathrm{mg}$ of TFV were weighed, powdered and average weight was calculated. Tablet powder equivalent to $30 \mathrm{mg}$ of TFV was transferred in to a $100 \mathrm{ml}$ volumetric flask. The drug was extracted by addition of methanol with shaking and the solution was filtered through Whatman filter paper (No.14). The volume was then made to the mark with methanol and filtered to obtain a concentration of $0.3 \mathrm{mg} / \mathrm{ml}, 0.025 \mathrm{mg} / \mathrm{ml}$ and 0.2 $\mathrm{mg} / \mathrm{ml}$. The formulation was assayed by spotting $2.5 \mu \mathrm{l}$ of the solution on to the plate followed by development and scanning HPTLC densitogram obtained from the sample solution shown in figure 3. Six determinations were performed.

\section{Results and Discussion}

Method development and optimization: Different mobile phases containing chloroform, hexane, toluene, methanol, ethyl acetate, formic acid and glacial acetic acid used in different proportions were examined. Chloroform: methanol: ethyl acetate: glacial acetic acid 5:2.1:0.1 ( $/ \mathrm{v} / \mathrm{v} / \mathrm{v} / \mathrm{v})$ was finally selected because it resulted in acceptable resolution of the bands with $\mathrm{R}_{f}$ values of $0.28 \pm 0.02$ for EMT, $0.71 \pm 0.02$ for RPV and $0.50 \pm 0.01$ for TFV.

\section{Method validation}

The method was validated as per ICH guideline parameters ICH Q2A (R1) 2005) used for the assay of a dosage form such as linearity, precision, accuracy, specificity quantification limit, detection limit and robustness. 
Linearity (plotting of calibration graph): Linearity of the method was studied by taking six calibration points for Emtricitabine, Rilpivirine and Tenofovir disoproxil fumarate. The mixed standard solutions in the concentration range of $400-2400 \mathrm{ng} / \mathrm{band}$ of Emtricitabine, 50 - $300 \mathrm{ng} / \mathrm{band}$ of Rilpivirine and 600 - $3600 \mathrm{ng} / \mathrm{band}$ of Tenofovir disoproxil fumarate injected 6 times into the CAMAG HPTLC system keeping the injection volume constant with correlation coefficients of $0.9998 \pm 0.002,0.9994 \pm 0.0055$ and $0.9991 \pm 0.0027$ shown in the table 1 . Calibration curve of emtricitabine, rilpivirine and tenofovir disoproxil fumarate were shown in figure 4. Plots of residuals against the concentrations of drugs showed the residuals were distributed both above and below the zero residual line shown in figure 5 .

Table 1. Method validation parameters of Emtricitabine, rilpivirine and Tenofovir disoproxil fumarate.

\begin{tabular}{lccc}
\hline \multicolumn{1}{c}{ Parameters } & Emtricitabine & Rilpivirine & $\begin{array}{c}\text { Tenofovir disoproxil } \\
\text { fumarate }\end{array}$ \\
\hline Detection wavelength & $272 \mathrm{~nm}$ & $272 \mathrm{~nm}$ & $272 \mathrm{~nm}$ \\
Linearity range (ng/band) & $400-2400$ & $50-300$ & $600-3600$ \\
Linearity equation & $\mathrm{y}=6.5963 \mathrm{x}+239.51$ & $\mathrm{y}=50.5197 \mathrm{x}+64.8098$ & $\mathrm{y}=3.9349 \mathrm{x}+219.92$ \\
Slope & 6.5963 & 50.5197 & 3.9349 \\
Intercept & 239.51 & 64.8098 & 219.92 \\
Correlation coefficient $\mathrm{r}$ & $0.9992 \pm 0.002$ & $0.9995 \pm 0.0055$ & $0.9993 \pm 0.0027$ \\
Standard deviation, $\mathrm{n}=6$ & 0.52 & 1.12 & 0.68 \\
Limit of detection (ng/band) & 5.0164 & 4.2500 & 5.5063 \\
Limit of quantification ng/band) & 15.2012 & 12.8790 & 16.6890 \\
\hline
\end{tabular}

Table 2. Assay results of fixed dose combined tablets (n=6).

\begin{tabular}{lccc}
\hline Parameters & Emtricitabine & Rilpivirine & Tenofovir \\
\hline Label claim (mg/tab) & $200 \mathrm{mg}$ & $25 \mathrm{mg}$ & $600 \mathrm{mg}$ \\
Actual amount added (ng/band) & $1000 \mathrm{ng}$ & $125 \mathrm{ng}$ & $1500 \mathrm{ng}$ \\
Amount obtained & $992.93 \pm 4.97$ & $123.66 \pm 1.97$ & $1496.83 \pm 3.86$ \\
(ng/band $\pm \mathrm{SD})$ & $99.29 \pm 0.48$ & $98.92 \pm 1.25$ & $99.78 \pm 0.81$ \\
drug content & 0.5008 & 1.1380 & 0.8120 \\
$\%$ RSD & & & \\
\hline
\end{tabular}

Table 3. Intra and inter-day precision for emtricitabine, rilpivirine and Tenofovir disoproxil fumarate $(\mathrm{n}=6)$.

\begin{tabular}{|c|c|c|c|c|c|c|c|}
\hline \multirow[b]{2}{*}{ Drug } & \multirow{2}{*}{$\begin{array}{l}\text { Amount labeled } \\
(\mathrm{mg} / \mathrm{tab})\end{array}$} & \multicolumn{2}{|c|}{ Percentage obtained* } & \multicolumn{2}{|c|}{ SD } & \multicolumn{2}{|c|}{$\%$ RSD } \\
\hline & & $\begin{array}{c}\text { Intra } \\
\text { day }\end{array}$ & $\begin{array}{c}\text { Inter } \\
\text { day }\end{array}$ & Intra day & Inter day & Intra day & Inter day \\
\hline \multirow{3}{*}{ Emtricitabine } & 200 & 99.58 & 99.56 & & & & \\
\hline & 200 & 100.35 & 100.12 & 0.5356 & 0.2967 & 0.5346 & 0.2970 \\
\hline & 200 & 100.61 & 100.01 & & & & \\
\hline \multirow[t]{2}{*}{ Mean } & & 100.18 & 99.89 & & & & \\
\hline & 25 & 98.96 & 99.15 & & & & \\
\hline \multirow{2}{*}{ Rilpivirine } & 25 & 99.78 & 100.37 & 0.4981 & 0.6630 & 0.5004 & 0.6656 \\
\hline & 25 & 99.86 & 99.31 & & & & \\
\hline Mean & & 99.53 & 99.61 & & & & \\
\hline Tenofovir & 300 & 100.13 & 99.56 & & & & \\
\hline Disoproxil & 300 & 100.51 & 99.67 & 0.2042 & 0.3650 & 0.2035 & 0.3656 \\
\hline fumarate & 300 & 100.45 & 100.24 & & & & \\
\hline Mean & & 100.36 & 99.82 & & & & \\
\hline
\end{tabular}


Table 4. Recovery study for EMT, RPV and TFV (n=3).

\begin{tabular}{|c|c|c|c|c|c|c|}
\hline Drug & $\begin{array}{l}\text { Amount added } \\
\text { (ng/band) }\end{array}$ & $\begin{array}{l}\text { Amount estimated } \\
\text { (ng/band)* }\end{array}$ & $\begin{array}{l}\text { Amount } \\
\text { recovered } \\
\text { (ng/band) }\end{array}$ & $\begin{array}{c}\% \\
\text { Recovery }\end{array}$ & S.D & $\begin{array}{c}\% \\
\text { RSD }\end{array}$ \\
\hline \multirow{4}{*}{ EMT } & 800 & 1800.197 & 807.2555 & 100.90 & \multirow{4}{*}{0.2454} & \multirow{4}{*}{0.2429} \\
\hline & 1000 & 2001.925 & 1008.9835 & 100.89 & & \\
\hline & 1200 & 2208.861 & 1215.9195 & 101.32 & & \\
\hline & & & $\begin{array}{c}\text { Mean } \\
\text { C.I }\end{array}$ & $\begin{array}{c}101.03 \\
100.42-101.63\end{array}$ & & \\
\hline \multirow{4}{*}{ RPV } & 100 & 225.649 & 101.9805 & 101.98 & \multirow{4}{*}{1.0533} & \multirow{4}{*}{$1.034 \mathrm{C}$} \\
\hline & 125 & 252.091 & 128.4225 & 102.73 & & \\
\hline & 150 & 274.653 & 150.9845 & 100.65 & & \\
\hline & & & $\begin{array}{c}\text { Mean } \\
\text { C.I }\end{array}$ & $\begin{array}{c}101.78 \\
99.16-104.39\end{array}$ & & \\
\hline \multirow{4}{*}{ TFV } & 1200 & 2706.141 & 1209.362 & 100.78 & \multirow{4}{*}{0.1892} & \multirow{4}{*}{0.1882} \\
\hline & 1500 & 3004.033 & 1507.254 & 100.48 & & \\
\hline & 1800 & 3304.642 & 1807.863 & 100.43 & & \\
\hline & & & $\begin{array}{c}\text { Mean } \\
\text { C.I }\end{array}$ & $\begin{array}{c}100.56 \\
100.09-101.03\end{array}$ & & \\
\hline
\end{tabular}

${ }^{1}$ Average value \pm relative standard deviation from three analyses

Table 5. Effect of mobile phase composition and volume variation on $\mathbf{R}_{f}$ values.

\begin{tabular}{|c|c|c|c|}
\hline \multirow{2}{*}{$\begin{array}{l}\text { Mobile phase composition, } \mathrm{v} / \mathrm{v} / \mathrm{v} / \mathrm{v} \text { chloroform: ethyl } \\
\text { acetate: methanol: glacial acetic acid }\end{array}$} & \multicolumn{3}{|c|}{$\mathrm{R}_{f}$ value } \\
\hline & EMT & RPV & TFV \\
\hline 5.0:2.0:1.0:0.1 (optimized) & 0.28 & 0.70 & 0.52 \\
\hline $5.0: 1.5: 1.5: 0.1$ & 0.26 & 0.67 & 0.47 \\
\hline $5.0: 1.5: 2.0: 0.1$ & 0.27 & 0.65 & 0.51 \\
\hline 5.0:2.0:1.5:0.1 & 0.29 & 0.66 & 0.51 \\
\hline $4.5: 2.5: 1.0: 0.2$ & 0.32 & 0.67 & 0.49 \\
\hline $4.5: 1.5: 1.5: 0.1$ & 0.29 & 0.72 & 0.51 \\
\hline
\end{tabular}

Table 6. Peak area Robustness study for the developed method (n=6).

\begin{tabular}{lccc}
\hline \multirow{2}{*}{ Parameter studied } & \multicolumn{3}{c}{$\%$ RSD } \\
\cline { 2 - 4 } & EMT & RPV & TFV \\
\hline Composition of mobile phase $( \pm 2 \%)$ & 0.98 & 1.31 & 1.27 \\
Volume of mobile phase $( \pm 5 \%)$ & 1.34 & 1.29 & 1.38 \\
Time from spotting to development $(10 \mathrm{~min})$ & 0.61 & 0.87 & 0.72 \\
Time from development to scanning $(10 \mathrm{~min})$ & 0.68 & 0.74 & 0.83 \\
\hline
\end{tabular}

*\% RSD were calculated from the peak areas of densitograms

Table 7. Stability of the plate.

\begin{tabular}{ccccc}
\hline \multirow{2}{*}{ Volume applied } & Time in hours & \multicolumn{3}{c}{ Peak area } \\
& & EMT & RPV & TFV \\
\hline \multirow{3}{*}{$2.5 \mu \mathrm{l}$} & 1 & 4672.64 & 4922.31 & 4277.17 \\
& 2 & 4642.12 & 4909.36 & 4249.73 \\
& 4 & 4654.34 & 4914.83 & 4264.22 \\
& 7 & 4606.48 & 4894.97 & 4237.34 \\
& & 4622.72 & 4889.23 & 4228.39 \\
\hline
\end{tabular}


<smiles></smiles>

1a<smiles>CC(C)OC(=O)OCOP(=O)(CO[C@@H](C)Cn1cnc2c(N)ncnc21)OCOC(=O)OC(C)C</smiles>

$1 b$<smiles>Cc1cc(/C=C/C#N)cc(C)c1Nc1ccnc(Nc2ccc(C#N)cc2)n1</smiles>

$1 \mathrm{c}$

Figure 1. Chemical structure of EMT, RPV and TFV.

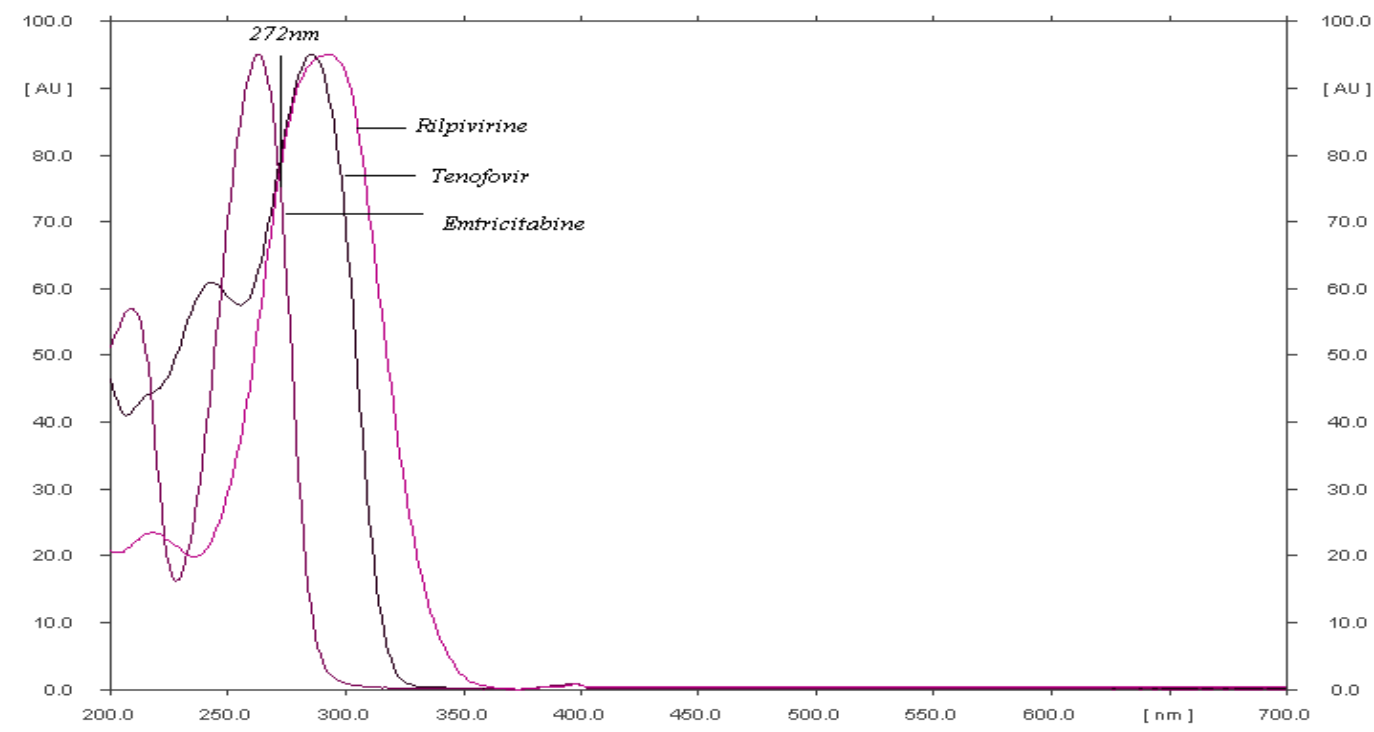

Figure 2. Overlain spectra of EMT, RPV and TFV.
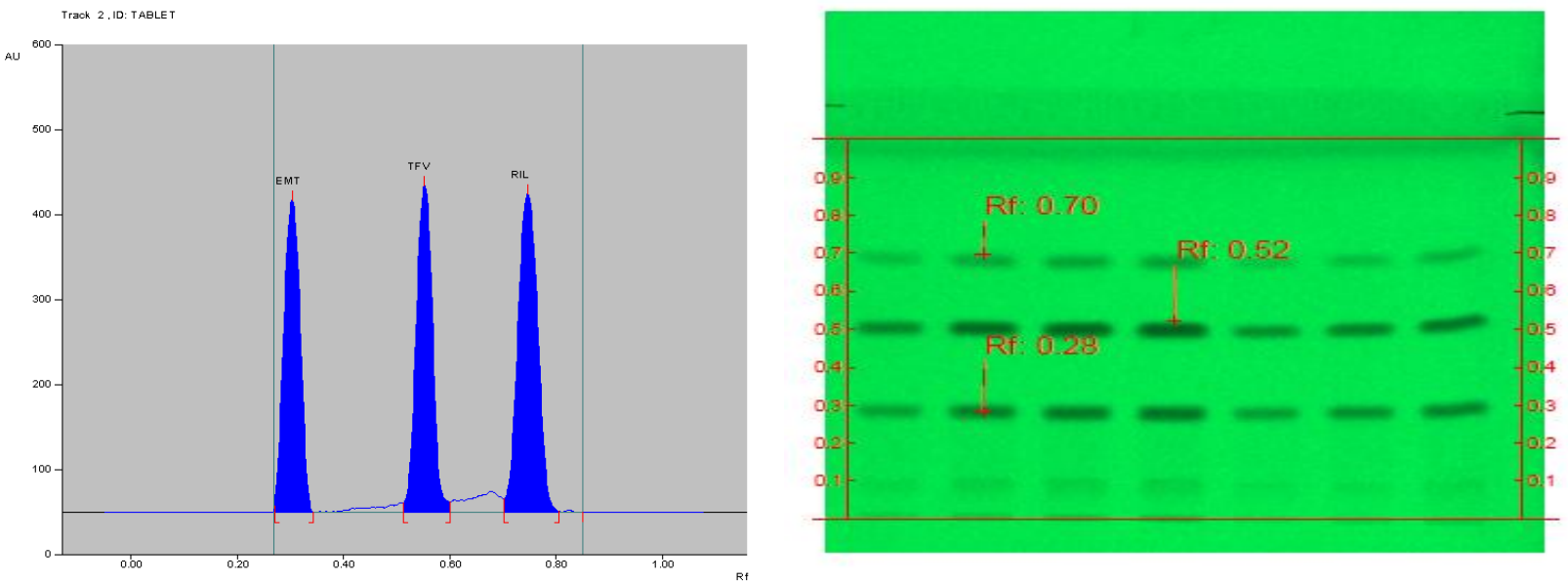

Figure 3. HPTLC densitogram obtained from the sample solution of EMT ( $\left.1000 \mathrm{ng} / \mathrm{band}, \mathrm{R}_{f}=0.28 \pm 0.02\right), \mathrm{RPVe}(125 \mathrm{ng} / \mathrm{band}$, $\left.\mathrm{R}_{f}=0.70 \pm 0.02\right)$ and TFV $\left(1500 \mathrm{ng} / \mathrm{band}, \mathrm{R}_{f}=0.52 \pm 0.04\right) @ 272 \mathrm{~nm}$. 

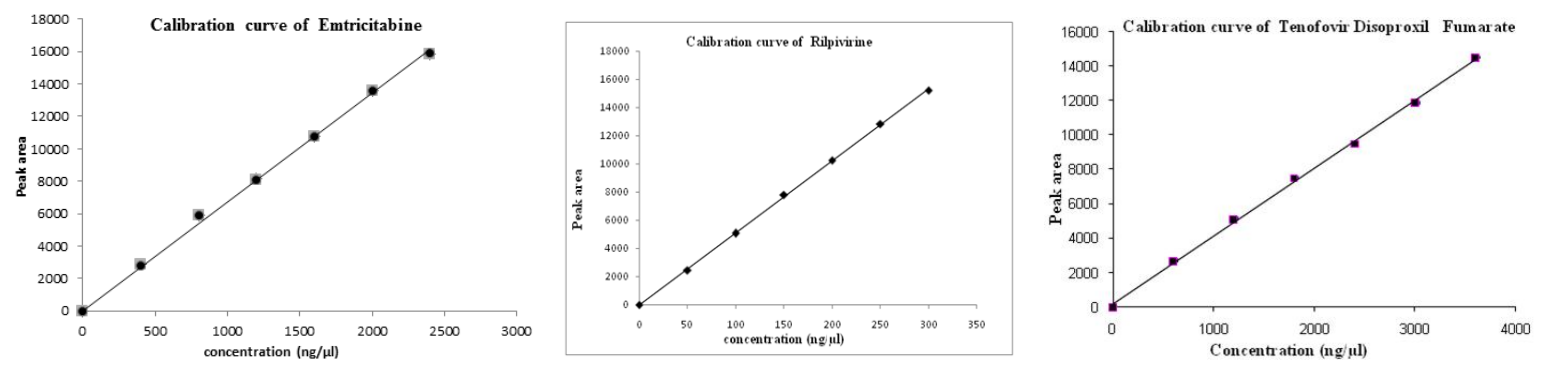

Figure 4. Calibration curve of EMT, RPV and TFV.
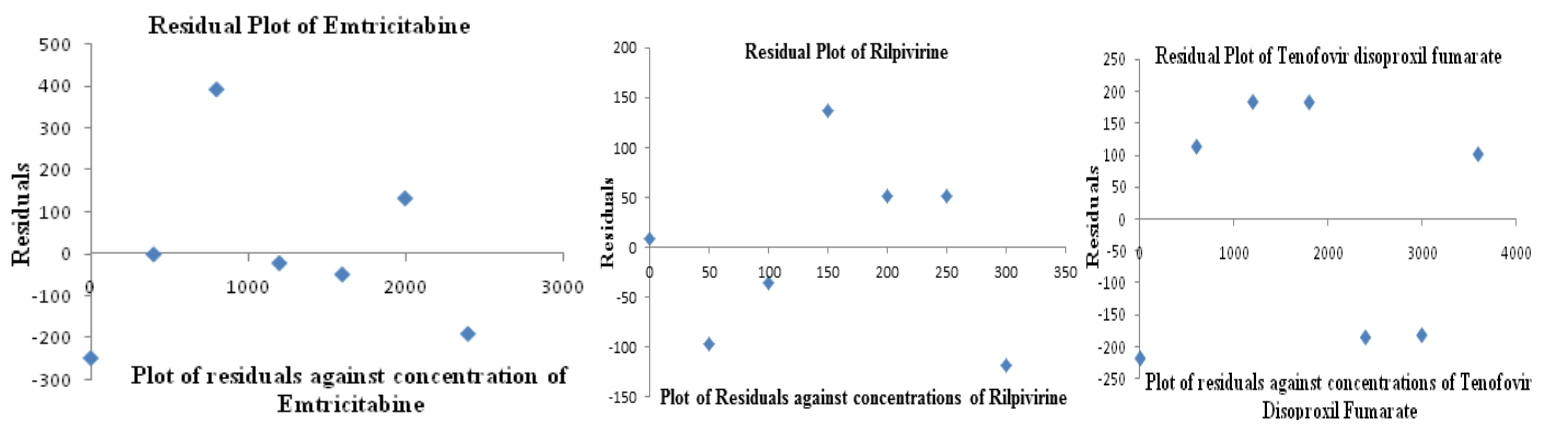

Figure 5. Plot of residuals against various concentrations.

Precision: To study the precision, Intra-day and Inter-day precision was studied by taking three different concentrations 800, 1200 and $1600 \mathrm{ng} / \mathrm{band}$ of EMT, 100, 150 and $200 \mathrm{ng} / \mathrm{band}$ of RPV and 1200, 1800 and $2400 \mathrm{ng} / \mathrm{band}$ of TFV and three replicates of each concentration to see the variation of their peak area within a day and for three different days. Six replicate analyses were performed on accurately weighed amounts of the tablets. The assay (\%) was found to be $99.29 \pm 0.48$ for EMT, $98.92 \pm 1.25$ for RPV and 99.78 \pm 0.81 for TFV, with \% RSD values of $0.50,1.59$ and 0.25 , respectively shown in table 2 . Intra-day Precision, as $\operatorname{RSD}(\%)$, was found to be 0.56 for EMT, 0.56 for RPV and 0.81 for TFV, with standard error of 0.34 , 0.24 and 0.56 , respectively. Interday Precision, as RSD (\%), was found to be 0.80 for EMT, 0.80 for RPV and 1.90 for TFV, with standard error of $0.43,0.42$ and 1.09 shown in table 3.

Accuracy: To study the recovery of formulation, standard drugs of EMT, RPV and TFV at 80\%, 100\%, $120 \%$ were added to the labeled claim of EMT $200 \mathrm{mg}$ (i.e. the spiked amounts were 800, 1000, 1200 ng/band). To study the recovery of RPV, standard were added to the labeled claim equivalent of RPV $25 \mathrm{mg}$ (i.e. the spiked amounts were 80, 100 and $120 \mathrm{ng} / \mathrm{band}$ ). Similarly, to study recovery of TFV, standards were added to the labeled claim of TFV $300 \mathrm{mg}$ (i.e. the spiked amounts were 1200, 150, $1800 \mathrm{ng} / \mathrm{band}$ ). For EMT, \% recovery ranged from $100.01 \pm 0.42 \%$, with 95\% confidence interval ranging from 98.95 $101.06 \%$. For RPV, \% recovery ranged from $100.32 \pm$ $0.48 \%$, with $95 \%$ confidence interval ranging from 99.12 - 101.51. For TFV, \% recovery ranged from $100.14 \pm 0.05 \%$, with $95 \%$ confidence interval ranging from $99.99-100.28 \%$ found to be within the limits shown in table 4.

Limit of detection and quantification: Determinations of limit of detection and quantification were based on the standard deviation of the response and the slope as:

$$
\mathrm{LOD}=3.3 \sigma / \mathrm{S} \text {, and } \mathrm{LOQ}=10 \sigma / \mathrm{S}
$$

Where $\sigma$ is the standard deviation of y-intercepts of regression line and $\mathrm{S}$ is the slope of the corresponding standard curve. LOD and LOQ were determined by measuring the magnitude of analytical background by spotting a blank and calculating the signal-to-noise ratio for EMT, RPV and TFV by spotting a series of solutions until the $\mathrm{S} / \mathrm{N}$ ratio 3 for $\mathrm{LOD}$ and 10 for $\mathrm{LOQ}$. The 
LOD and LOQ were 5.0164 and $15.2012 \mathrm{ng} / \mathrm{band}$ for EMT, 4.25 and $12.8790 \mathrm{ng} / \mathrm{band}$ for RPV and 5.5063 and $16.6890 \mathrm{ng} / \mathrm{band}$ for TFV shown in table 1 .

Specificity: The specificity of the method was confirmed by comparing the $\mathrm{R}_{f}$ values and spectra of the spots with that standards and test samples. The peak purity of samples was assessed by comparing the spectra at three different levels, i.e., peak start (S), peak apex (M) and peak end (E) positions of the spot. The peak purity was determined on WinCATS software V 1.4.6. Acceptable peak purity and correlation values suggest no interference in the quantification of analyzed drugs in sample solutions. This proves that the method were specific.

Robustness: The robustness was studied by evaluating the effect of small but deliberate variations in the chromatographic conditions. Small changes in the mobile phase composition $( \pm 0.1 \mathrm{ml})$, the effect on the results were examined. Concentrations of $800 \mathrm{ng} / \mathrm{band}$ for EMT, $100 \mathrm{ng} / \mathrm{band}$ for RPV and $1200 \mathrm{ng} / \mathrm{band}$ for TFV were applied to study the robustness of the method. The effect of these changes on $\mathrm{R}_{f}$ values and peak area was evaluated by calculating the relative standard deviations (RSD) for each parameter. Mobile phases having different proportions of components, e.g. chloroform: ethylacetate: methanol: glacial acetic acid in the ratio of 5:1.5:1.5:0.1 v/v/v/v, 5:1.5:2:0.1 v/v/v/v, 5:2.0:1.5:0.1 $\mathrm{v} / \mathrm{v} / \mathrm{v} / \mathrm{v}, \quad 4.5: 2.5: 1: 0.2, \quad 4.5: 1.5: 1.5: 0.1$ $\mathrm{v} / \mathrm{v} / \mathrm{v} / \mathrm{v}$ etc., were tried shown in table 5 . The time from spotting to chromatography and from chromatography to scanning was varied by $10 \mathrm{~min}$ and analysed. The robustness of the method was determined at different proportions of mobile phase. The effect of changes on $\mathrm{R}_{f}$ values and peak area was evaluated by calculating the relative standard deviations (RSD) for each parameter. The peak areas were unaffected (RSD $<2 \%$ ) by small changes of the operating conditions. The results from the robustness study listed in table 6 .

Stability study: The stability of the drugs on the TLC plates, the freshly prepared drug solutions were applied to the plates and developed at a room temperature. The sample solutions were spotted at initial, $1 \mathrm{hr}, 2 \mathrm{hr}, 4 \mathrm{hr}$ and $7 \mathrm{hrs}$. No decomposition of the drug was observed during densitogram development. No significant decrease in peak area was found for a stock solution after storage at room temperature for 7 hours. These observations suggest that all the drugs were stable for 7 hrs shown in table 7 .

\section{Conclusion}

The validated HPTLC method employed here proved to be simple, rapid, accurate, precise and robust and can thus be used for routine analysis of EMT, RPV and TFV in a combined tablet dosage form.

\section{Acknowledgement}

The authors would like to express their gratitude to Strides Arcolabs, Bengaluru for providing pure samples of Emtricitabine, Rilpivirine, and Tenofovir disoproxil fumarate. Also utilizing their facilities in Interdisciplinary Science of Indian System of Medicine, SRM University, Chennai. The authors thankful to Sakthi Arulthiru Amma and Thirumathi Amma, ACMEC Trust, Melmaruvathur for providing the necessary facilities to complete out this research successfully.

\section{References}

Ahindita, B., Aurobinda, P., Amit, G.S., Dannana, G.S., Swapna, K.M. and Sudam, C.S.I. 2011. Development and validation of spectrophotometric methods for determination of emtricitabine and tenofovir disoproxil fumarate in bulk and tablet dosage form. Int. J. Pharm. Tech. Res. 3, 1874-1882.

Anandakumar, K., Kannan, K. and Vetrichelvan, T. 2011. Development and validation of emtricitabine and Tenofovir disoproxil fumarate in pure and in fixed dose combination by uv spectrophotometry. Dig. J. Nanomat. Biostructures 6, 1085-1090.

Choudhari, V.P., Parekar, S.R., Chate, S.G., Bharande, P.D., Singh, R.R. and Kuchekar, B.S. 2013. Development and Validation of UV-Visible Spectrophotometric Baseline Manipulation Method for Simultaneous Quantitation of Tenofovir Disoproxil Fumarate and Emtricitabine in Pharmaceutical Dosage Form. J. Spectroscopy 6.

Choudhari, V.P., Ingale, K.D., Barhate, A., Kale, A.N., Bobade, C.D. and Kuchekar, B.S. 2010. Development and validation of Simultaneous and Isoabsorptive UV Spectrophotometric methods for Tenofovir and Emtricitabine in Pharmaceutical Formulations. J. Pharm. Res. 9, 11-13. 
Ghorpade, S.A., Sali, M.S., Kategaonkar, A.H, Patel, D.M., Choudhari, V.P. and Kuchekar, B.S. 2010. Simultaneous determination of emtricitabine and tenofovir by area under curve and dual wavelength spectrophotometric method. J. Chil. Chem. Soci. 54, 331-333.

Indian Pharmacopoeia. 2014, Government of India, Ministry of Health and Family Welfare, The Indian pharmacopoeia commission, New Delhi. 2: 953.

ICH: Harmonised Tripartite Guideline, Validation of analytical procedures: text and methodology, International Conference on Harmonization. Q2(R1), Geneva, Nov 2005. 1-13.

Ilango, K. and Sunitha, P.G. 2012. Development and validation of UV spectrophotometric methods for the simultaneous determination of Emtricitabine and Tenofovir in combined dosage form. J. Pharm. Res. 5, 873-875.

Jayakar, B., Kumudhavalli, M.V., Koteswara Rao, V.P., Saravanan, V.S., Margret Chandira, C. and Abhitej, R. 2010. Method development and validation for simultaneous estimation of Emtricitabine and tenofovir disoproxil fumarate in Pharmaceutical dosage form. Ann. Pharm. Pharm. Sci. 2, 152-154.

Joshi, M., Nikalje, A.P., Shahed, M. and Dehghan, M. 2009. HPTLC method for the simultaneous Estimation of emtricitabine and tenofovir in tablet dosage form. Ind. $J$. Pharm. Sci. 71, 95-99.
Murali pendela, Getu weldu kahsay, Guy van den mooter, Lieven baert, Jos hoogmartens, Erwin adams. 2011. LC Assay for a HIV Tablet Containing Emtricitabine, Tenofovir Disoproxil Fumarate and Rilpivirine. Chromatographia 73, 439-445.

Patel, S., Baghel, U.S., Rajesh, P., Prabhakar, D., Engla, G. and Nagar, P.N. 2009. Spectrophotometric method development and validation for simultaneous estimation of tenofovir disoproxil fumarate and emtricitabine in bulk drug and tablet dosage form. Int. J. Pharm. Clin. Res. 1, 28-30.

Pranitha, D., Vanitha, C., Prince Francis, Alagar Raja, M., Vishnu Vardan, P., Surendar, M. and Banji, D. 2012. Simultaneous estimation of emtricitabine, tenofovir disoproxil fumarate and rilpivirine in bulk form by RPHPLC method. J. Pharm. Res. 5, 4600-4602.

Rao, J.R., Gondkar, S.A. and Yadav, S.S. 2011. Simultaneous HPTLC- Densitometric analysis of Tenofovir and Emtricitabine in tablet dosage Form, Int. J. Pharm. Tech. Res. 3, 1430-1434.

Rezk, N.L, Crutchley, R.D. and Kashuba, A.D. 2005. Simultaneous quantification of Emtricitabine and tenofovir in human plasma using high-performance liquid chromatography after solid phase extraction, $J$. Chromatogr. B. 822, 201-208. 